\title{
Ophthalmologica
}

Becker, M.D. 39

Clemens, C.R. 28

Eter, N. 28

Fischer, M.D. 48

Freiberg, F.J. 39

Haritoglou, C. 1

Henrich, P.B. 1

Ikeda, Y. 21

Ishibashi, T. 21
Jacob, J. 9

Kobayashi, Y. 21

Koyanagi, Y. 21

Kubo, Y. 21

Macky, T.A. 16

Mahgoub, M.M. 16

Mayer, W.J. 1

Michels, S. 39

Nakama, T. 21

Nakao, S. 21

Ohshima, Y. 21

Pfau, M. 39
Scheler, R. 1

Schumann, R.G. 1

Sonoda, K. 21

Spindler, V. 1

Stalmans, P. 9

Vielmuth, F. 1

Wirth, M.A. 39

Wolf, A. 1

Wons, J. 39

Yamaguchi, M. 21

Yoshida, S. 21

\section{Subject Index Vol. 238, Suppl. 1, 2017}

Adhesión vitreomacular 9

Agudeza visual 21

Angiografía 39

Anti-VEGF 21

Cambio en la interfase vitreomacular 9

Cirugía vitreoretiniana 48

Degeneración macular relacionada con la edad 28

Desgarro del epitelio pigmentario de la retina 28

Desprendimiento de vítreo posterior 9

- del epitelio pigmentario de la retina 28

Distrofia retiniana 48
Edema macular diabético 21

Epitelio pigmentario de la retina 28

Inyección intravítrea 28

Láser de argón convencional 16

Maculopatía diabética 16

Membrana limitante interna 1

Oclusión venosa de la retina 39

Ocriplasmina 1
Panfotocoagulación 16

Pascal $^{\circledR}$ fotocoagulador 16

Retinopatía diabética proliferativa 16

Terapia génica 48

Tomografía de coherencia óptica 9, 21, 39

- $\quad$ _ $\quad$ de dominio espectral 28

Tracción vitreomacular 1,9

Vitrectomía 21

Zona avascular foveal 39

\section{KARGER}

